\title{
Mengeksplorasi Kemampuan Siswa Dalam Berpikir Fungsional Melalui Soal Cerita
}

\author{
Suci Yuniati ${ }^{1}$, Suparjono ${ }^{2}$ \\ ${ }^{1}$ Program Studi Pendidikan Matematika, Fakultas Tarbiyah dan Keguruan, Universitas Islam Negeri Suska Riau \\ ${ }^{2}$ Program Studi Manajemen Dakwah, Fakultas Tarbiyah dan Keguruan, Universitas Islam Negeri Suska Riau, \\ Jl. Hr. Subrantas No. 55 Panam, Riau, Indonesia \\ suci.yuniati@uin-suska.ac.id
}

\begin{abstract}
The shift about students 'ability to solve arithmetic with numerical operations to students' ability to solve algebra by operating on unknown numbers often experiences difficulties. Thus, to overcome these student difficulties, it is necessary to exercise and stimulate students' abilities, one of which is by training students in functional thinking. Functional thinking is a relationship between two quantities which are generalized into a function. This study aims to explore students' ability to think functionally through story problems. This research is a qualitative descriptive exploratory research. The research subjects were 3 students from 45 high school students (SMA). The research instruments were student answer sheets and interview guidelines. The results showed that students in functional thinking through 3 stages, namely students determining recursive patterns using $b=U_{n}-U_{(n-1)}$, students determining correspondence relationships, namely determining changes in values between the independent variables and the dependent variable, and students determining correspondence. by using the arithmetic sequence formula. Thus it can be concluded that the given story problem can explore students in functional thinking.
\end{abstract}

Keywords: Functional Thinking, Story problem, Function.

\begin{abstract}
Abstrak
Pergeseran tentang kemampuan siswa dalam memecahkan aritmetika dengan operasi angka ke kemampuan siswa dalam memecahkan aljabar dengan operasi pada bilangan yang tidak diketahui sering mengalami kesulitan. Dengan demikian untuk mengatasi kesulitan siswa tersebut, maka perlu adanya latihan dan rangsangan terhadap kemampuan siswa yaitu salah satunya dengan melatih siswa dalam berpikir fungsional. Berpikir fungsional merupakan hubungan antara dua kuantitas yang digeneralisasikan ke dalam suatu bentuk fungsi. Penelitian ini bertujuan untuk mengeksplorasi kemampuan siswa berpikir fungsional melalui soal cerita. Penelitian ini merupakan penelitian kualitatif yang bersifat deskriptif eksploratif. Subjek penelitian adalah 3 siswa dari 45 siswa Sekolah Menengah Atas (SMA). Instrumen penelitian adalah lembar jawaban siswa dan pedoman wawancara. Hasil penelitian menunjukan bahwa siswa dalam berpikir fungsional melalui 3 tahap yaitu siswa menentukan pola rekursif dengan menggunakan $b=U_{n}-U_{(n-1)}$, siswa menentukan hubungan korespondensi yaitu menentukan perubangan nilai antara variabel bebas dengan variabel terikat, dan siswa menentukan korespondesi dengan menggunakan rumus barisan aritmatika. Dengan demikian dapat disimpulkan bahwa soal cerita yang diberikan dapat mengeksplorasi siswa dalam berpikir fungsional.
\end{abstract}

Kata Kunci: Berpikir fungsional, Soal cerita, Fungsi.

Copyright (c) 2021 Suci Yuniati, Suparjono

$\bowtie$ Corresponding author: Suci Yuniati

Email Address: suci.yuniati@uin-suska,.ac.id (Jl. H.R Soebrantas, No 55, Panam, Riau)

Received 20 Januari 2021, Accepted 29 Januari 2021, Published 14 Februari 2021

\section{PENDAHULUAN}

Kebanyakan pendidik pada umumnya percaya bahwa aritmetika merupakan dasar dari aljabar yang perlu diajarkan di sekolah. Pernyataan tersebut tercermin dalam kurikulum matematika bahwa aritmetika diajarkan terlebih dahulu di sekolah dasar kemudian aljabar. Namun, Carpenter \& Levi (2000) menyatakan bahwa pemisahan aritmetika dan aljabar pada skema pemikiran anak di sekolah dasar akam membuat siswa kesulitan dalam belajar aljabar di tahun-tahun berikutnya. Dengan kata lain bahwa siswa yang terbiasa pada kerangka acuan aritmetika akan cenderung pada perhitungan 
tanpa melihat aspek relasional dari operasi. Seharusnya siswa mulai bergeser dari pengetahuan dalam memecahkan aritmetika dengan operasi angka ke pengetahuan dalam memecahkan aljabar dengan operasi pada bilangan yang tidak diketahui. Dengan demikian perlu dikembangkan cara berpikir aljabar. Berpikir aljabar adalah kemampuan mengoperasikan kuantitas yang seolah-olah tidak diketahui kuantitasnya atau didefinisikan sebagai kapasitas untuk mewakili situasi kuantitatif sehingga hubungan antar variabel akan terlihat (Driscoll, 2003). Menurut Kaput (2000) dan Blanton, et al. (2015) dalam mengidentifikasi berpikir aljabar ada lima komponen yaitu 1) generalisasi dan memformalisasikan pola dan constraints, 2) memanipulasi formalisasi, 3) menggunakan bahasa natural untuk mengartikulasikan struktur abstrak, 4) mempelajari fungsi, hubungan dan joint variation, dan 5) menggunakan bahasa dalam pemodelan dan pemodelan matematika. Berdasarkan komponen-komponen di atas, maka yang menjadi fokus dalam penelitian ini adalah berpikir fungsional.

Berpikir fungsional (functional thinking) merupakan jenis berpikir yang merepresentasikan hubungan antar dua (atau lebih) variasi kuantitas Smith (Markworth, 2010). Blanton \& Kaput (2005) menyatakan bahwa berpikir fungsional merupakan hubungan antar kuantitas tertentu yang dapat disebut sebagai aturan "korespondensi". Di sisi lain Blanton, dkk. (2015) menyatakan bahwa berpikir fungsional merupakan generalisasi hubungan antar variasi kuantitas, penalaran dan merepresentasikan hubungan tersebut melalui bahasa natural, notasi aljabar (simbol), tabel, dan grafik. Blanton, dkk. (2015) memberikan contoh tugas berpikir fungsional yaitu tentang "pemotongan tali: hubungan antara banyak pemotongan tali dan banyak potongan tali yang dihasilkan”, maka tipe fungsi yang dapat dibentuk $\mathrm{y}=\mathrm{x}+1$, dimana $\mathrm{x}=$ banyak pemotongan tali dan $\mathrm{y}=$ banyak potongan tali yang dihasilkan. Dengan demikian, berpikir fungsional merupakan hubungan antara dua kuantitas yang digeneralisasikan ke dalam suatu bentuk fungsi yang sesuai.

Blanton \& Kaput (2011) dan Tanişli (2011) dalam penelitiannya menggunakan tiga komponen berpikir fungsional, yaitu (1) recursive patterning meliputi penemuan variasi dalam suatu barisan nilai, (2) covariational thinking yang didasarkan pada analisis bagaimana dua variasi kuantitas secara simultan dan memahami bahwa perubahan sebagai suatu yang eksplisit dan bagian dinamis serta deskripsi fungsi, dan (3) hubungan korespondensi didasarkan pada korelasi antara variabel. Misalnya siswa diminta menentukan bilangan kesepuluh dari pola bilangan 2, 4, 6, 8. Dalam hal ini siswa telah melakukan berpikir fungsional, yaitu mengaitkan bilangan pertama dipasangkan dengan 2, bilangan kedua dipasangkan dengan bilangan 4 , bilangan ketiga dipasangkan dengan bilangan 6 , dan seterusnya, akhirnya sampai pada bilangan kesepuluh dengan bilangan 20, dan pada bilangan ke- $\mathrm{n}$ dengan bilangan $2 \times \mathrm{n}$.

Berpikir fungsional telah dikaji oleh banyak peneliti diantaranya: Blanton, dkk, 2016; Blanton, dkk, 2015; Blanton \& Kaput, 2004; Brizuela, dkk., 2015; Cooper, 2006; Muir \& Livy, 2015; Tanıs, 2011; Warren \& Cooper, 2012; Warren \& Cooper, 2005. Secara umum hasil penelitian tersebut menunjukan bahwa siswa mampu memahami hubungan antara variasi kuantitas dan mulai berpikir 
secara fungsional. Misalnya Blanton, dkk. (2015) menemukan 8 level kemapuan siswa dalam berpikir fungsional. Blanton \& Kaput (2005); Doorman, dkk (2012); Stephens (2017); Stephens, dkk (2017); Warren, dkk (2006); Wilkie (2004); Wilkie (2015); Wilkie \& Clarke (2015); Wilkie \& Clarke (2016) merancang pembelajaran yang dapat meningkatkan peserta didik dalam berpikir fungsional. Kemudian, Mceldoon (2010) mengembangkan penilaian tentang kemampuan peserta didik Sekolah Dasar dalam berpikir fungsional, khususnya pada kemampuan peserta didik dalam menemukan aturan korespondensi dalam tabel fungsi. Allday (2017) melakukan penelitian tentang perilaku siswa dalam berpikir fungsional yang dapat membantu para guru untuk membuat keputusan dalam menentukan intervensi yang lebih baik. Wilkie (2014) melakukan penelitian kepada 105 guru sekolah dasar tentang bagaimana membelajarkan siswa berpikir fungsional dan menunjukan bahwa dua pertiga guru mengetahui konten tentang tugas generalisasi pola untuk sekolah dasar yang dapat mengeksplorasi berpikir fungsional. Berdasarkan penelitian-penelitian tersebut diatas, maka belum ada penelitian yang mengeksplorasi kemampuan berpikir fungsional dengan menggunakan soal cerita.

Soal cerita merupakan soal matematika yang berbentuk soal cerita dan menggunakan kalimat sehari-hari. Menurut Koedinger \& Nathan (2004) dan Yuniati \& Suparjono (2019) penyelesaian soal memerlukan keterampilan dalam memahami masalah, menentukan metode yang tepat, dan membangun model abstrak. Menurut Machmurotun (2014) soal cerita merupakan soal yang dibuat dalam bentuk cerita pendek atau kalimat sederhana yang bermakna dan dikaitkan dalam kehidupan sehari-hari. Penyelesaian soal cerita yang diperlukan bukan hasil penyelesaian, melainkan proses penyelesaian sehingga proses berpikir siswa dapat terlihat. Proses berpikir siswa tersebut merupakan kemampuan siswa yang akan dikaitkan dengan beberapa komponen berpikir fungsional.

\section{METODE}

Penelitian ini merupakan penelitian kualitatif yang bersifat deskriptif eksploratif. Subjek penelitian adalah 3 siswa dari 45 siswa Sekolah Menengah Atas (SMA). Subjek penelitian dipilih secara purposive sampling yaitu siswa yang menyelesaikan secara benar lembar tes dan memiliki kemampuan komunikasi yang lancar. Instrumen penelitian adalah lembar jawaban siswa dan pedoman wawancara. Wawancara digunakan untuk mendalami dan mengklarifikasi berpikir fungsional siswa yang belum terungkap ketika siswa menyelesaikan masalah dan yang tidak tertulis pada lembar jawaban. Adapun roadmap dalam penelitian ini dapat dilihat pada Diagram 1.

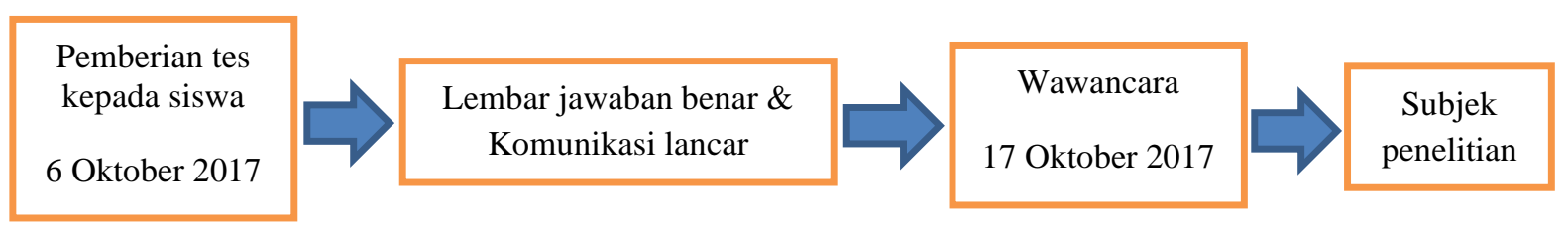

Diagram 1. Roadmap Penelitian

Bentuk soal yang digunakan adalah soal yang disusun berdasarkan suatu kasus atau kejadian untuk mengeksplor siswa dalam berpikir fungsional. Dalam soal tersebut terdapat variabel independen yang 
diwakili oleh "banyak baris" dan variabel dependen diwakili oleh "banyak meja dan banyak kursi". Lembar soal yang diberikan ke siswa dapat dilihat pada Gambar 1.

\section{Masalah 1}

Sekolah Adi Buana Surabaya akan mengadakan rapat Wali Murid di Gedung Serbaguna. Dalam gedung tersebut akan disusun meja dan kursi dengan baris paling depan disusun 4 meja dan 8 kursi, baris kedua disusun 5 meja dan 10 kursi, baris ketiga disusun 6 meja dan 12 kursi dan seterusnya.

a. Temukan cara untuk menemukan banyaknya meja pada baris ke-100. Jelaskan bagaimana kamu menemukan cara tersebut!

b. Temukan cara untuk menemukan banyaknya kursi pada baris ke-100. Jelaskan bagaimana kamu menemukan cara tersebut!

c. Temukan rumus untuk menentukan banyaknya meja pada baris ke-n. Jelaskan bagaimana kamu menemukan rumus tersebut!

d. Temukan rumus untuk menentukan banyaknya kursi pada baris ke-n. Jelaskan bagaimana kamu menemukan rumus tersebut!

e. Temukan rumus yang menyatakan hubungan antara banyaknya meja dan banyaknya kursi pada baris ke-n. Jelaskan bagaimana kamu menemukan rumus tersebut!

\section{Gambar 1. Lembar Soal}

Pada tahap analisis data, kegiatan yang dilakukan adalah 1) mengumpulkan semua lembar jawaban siswa; 2) menganalisis semua lembar jawaban siswa dan membuang data yang tidak sesuai (lembar jawaban salah); dan 3) kesimpulan, pada tahap ini peneliti menyimpulkan hasil penelitian (Creswell 2012).

\section{HASIL DAN DISKUSI}

Penelitian ini mengeksplorasi kemampuan siswa dalam berpikir fungsional. Komponen berpikir fungsional yang digunakan dalam penelitian ini adalah 1) menentukan pola rekursif; 2) menentukan hubungan kovariasional; dan 3) menentukan korespondensi. Komponen berpikir fungsional tersebut diadopsi dari penelitian Tanişli (2011) dan Blanton \& Kaput (2011). Temuan penelitian yang diperoleh peneliti adalah sebagai berikut:

\section{Menentukan Pola Rekursif}

Subjek S1 menjelaskan pola bilangan pada banyak meja pada baris pertama sampai baris ketiga secara berurutan dituliskan 4, 5, 6 dimana suku pertamanya 4, suku keduanya 5, suku ketiganya 6 . Dari pola bilangan tersebut subjek S1 mencari banyaknya meja merupakan kelipatan 1. Kemudian S1 menjelaskan pola bilangan pada banyak kursi pada baris pertama sampai baris ketiga secara berurutan dituliskan 8, 10, 12 dimana suku pertamanya 8, suku keduanya 10, suku ketiganya 12. Dari pola 
bilangan tersebut subjek S1 mencari banyaknya kursi merupakan kelipatan 2 atau mencari beda dengan menggunakan rumus $b=U_{n}-U_{n-1}$. Hal tersebut diperkuat oleh hasil lembar jawaban subjek S1 dalam menentukan pola rekursif seperti pada Gambar 2.

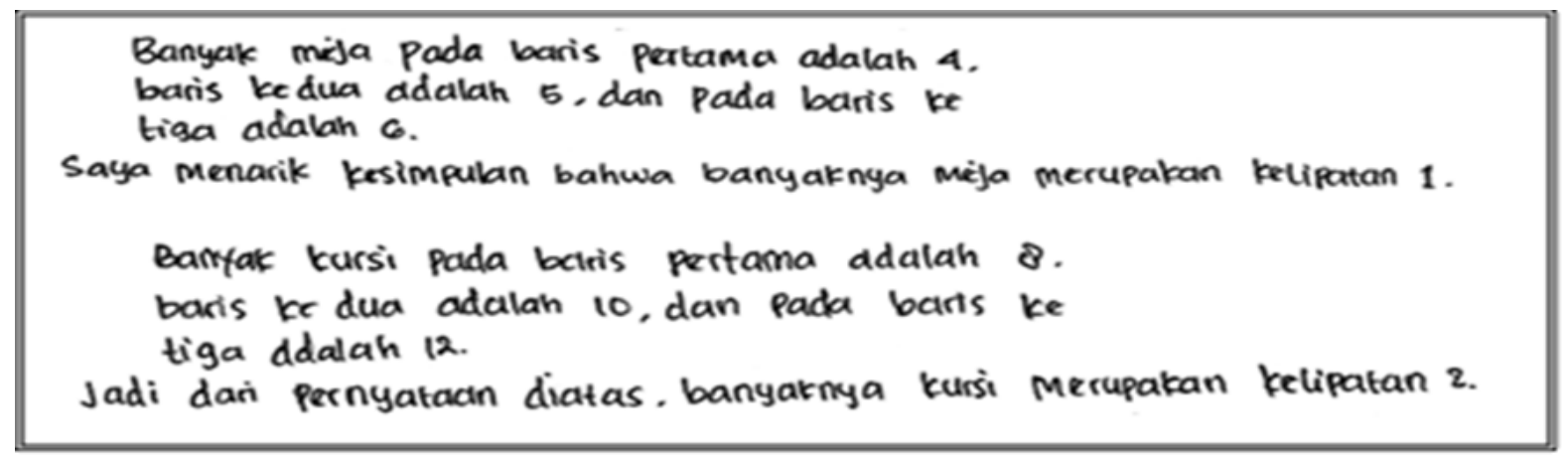

Gambar 2. Subjek S1 dalam Menentukan Pola Rekursif

\section{Menentukan Hubungan Kovariasional}

Dalam menentukan hubungan kovariasional, subjek S2 menentukan perubahan nilai antara letak suatu item dengan item itu sendiri yaitu jika letak baris meja mengalami perubahan 1 maka banyak meja terdapat perubahan nilai sebanyak 1 , jika letak baris kursi mengalami perubahan 1 maka banyak kursi terdapat perubahan nilai sebanyak 2 . Hal tersebut diperkuat dengan petikan wawancara peneliti dan subjek S5 berikut.

$P \quad$ : Coba perhatikan pola bilangan ini...jika kita lihat dari hubungan antar banyak baris dengan banyak meja, adakah perubahan nilai dari hubungan banyak baris dengan banyak meja?

S2 : Ada bu...

$P \quad$ : Berapa perubahan nilainya?

S2 : Jika banyak baris bertambah 1 maka banyak meja bertambah 1.

$P \quad:$ Terus...kalau hubungan banyak baris dengan banyak kursi, berapa perubahan nilainya?

S2 : Jika banyak baris bertambah 1 maka banyak kursi bertambah 2.

\section{Menentukan Korespondensi}

Dalam menentukan korespondensi, subjek S3 menggunakan rumus aritmatika $U_{n}=a+$ $(n-1) b$ untuk menentukan suku ke- $n$. Sehingga diperoleh $U_{n}$ untuk banyak meja adalah $U_{n}=n+$ 3; $U_{n}$ untuk banyak kursi adalah $U_{n}=2 n+6$. Hal tersebut diperkuat oleh hasil lembar jawaban subjek S3 dalam menggeneralisasikan hubungan antar kuantitas yang disajikan pada Gambar 3. 


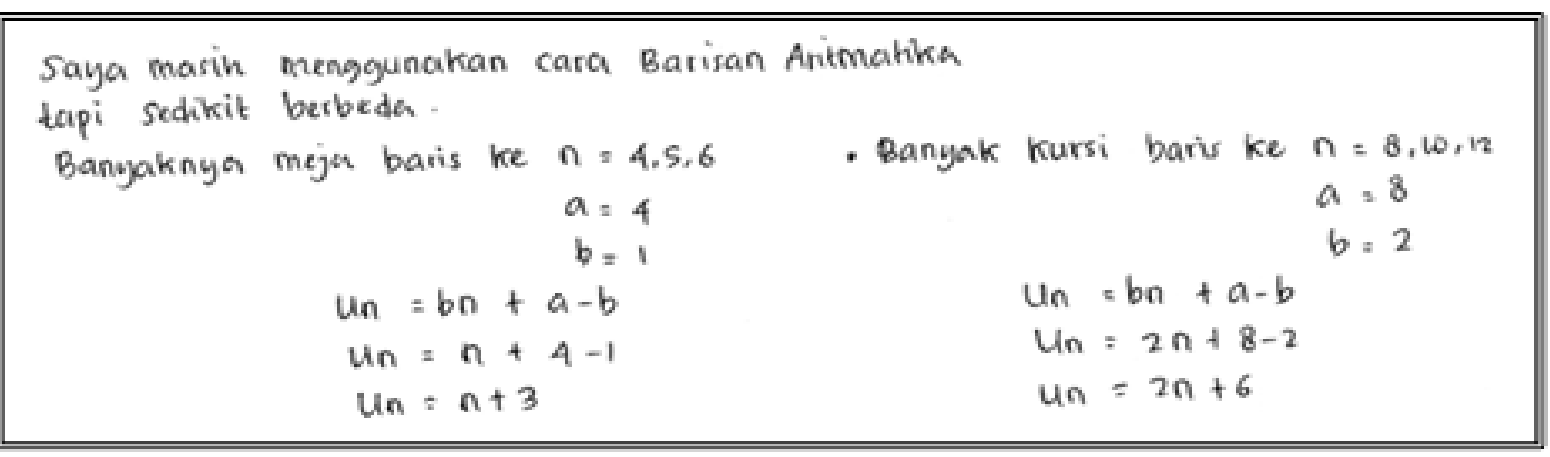

Gambar 3. Hasil Kerja Subjek S3 dalam Menentukan Korespondensi

Berdasarkan temuan penelitian, subjek menentukan pola rekursif dengan menuliskan data 1 dan data 2 secara berurutan dan membentuk suatu pola bilangan. Pola tersebut dicari dengan menggunakan rumus $b=U_{n}-U_{(n-1)}$, dimana $b=$ beda, $U_{n}=$ suku ke $n$, dan $U_{(n-1)}=$ suku sebelum $n$. Hal ini sesuai dengan pendapat Blanton \& Kaput (2011) dan Tanişli (2011) yang menyatakan bahwa pola rekursif adalah aktivitas mental dalam menentukan pola berdasarkan nilai sebelumnya. Kemudian pola rekursif dari data 1 dan data 2 dijadikan patokan subjek untuk menentukan hubungan kovariasional yaitu perubangan nilai antara variabel bebas dengan variabel terikat. Hal ini sesuai dengan pendapat Carlson, dkk. (2002); Blanton \& Kaput (2011); Subanji (2011); Tanişli (2011) yang menyatakan bahwa hubungan kovariasional adalah aktivitas mental dalam mengkoordinasikan dua kuantitas (variabel bebas dan variabel terikat) yang berkaitan dengan perubahan nilai dari satu kuantitas terhadap kuantitas yang lain. Dalam menentukan korespondensi subjek menggeneralisasikan data 1 dan menggeneralisasikan data 2 dengan menggunakan rumus dari barisan aritmatika yaitu $U_{n}=a+(n-1) b$. Namun, representasi yang digunakan subjek dalam menggeralisasikan hubungan antar variasi kovarian (korespondensi) menggunakan repersentasi aljabar. Hal ini sesuai dengan temuan penelitian Yuniati, dkk, (2019) bahwa siswa dalam menggeneralisasikan hubungan antar kuantitas (korespondensi) kebanyakan menggunakan representasi aljabar.

\section{KESIMPULAN}

Berdasarkan temuan dan hasil penelitian, maka dapat disimpulkan bahwa kemampuan siswa dalam berpikir fungsional melalui soal cerita adalah sebagai berikut: tahap pertama, siswa menentukan pola rekursif dengan menggunakan $b=U_{n}-U_{(n-1)}$, dimana $b=$ beda, $U_{n}=$ suku ke $n$, dan $U_{(n-1)}=$ suku sebelum $n$. Tahap kedua, siswa menentukan hubungan korespondensi yaitu perubangan nilai antara variabel bebas dengan variabel terikat. Tahap ketiga, siswa menggeneralisasikan hubungan antar variasi kuantitas (korespondesi) dengan menggunakan rumus dari barisan aritmatika yaitu $U_{n}=a+(n-1) b$. Bagi penelitian 
berikutnya yang berminat melakukan penelitian tentang berpikir fungsional dengan melakukan analisis kesalahan apa saja yang muncul ketika siswa melakukan berpikir fungsional.

\section{UCAPAN TERIMA KASIH}

Saya ucapkan terimakasih kepada guru bidang studi matematika yang telah memberikan ijin kepada peneliti untuk mengambil data dan kepada siswa SMA di salah satu Sekolah di Kota Pekanbaru yang telah bersedia dalam menyelesaikan soal yang saya berikan.

\section{REFERENSI}

Allday, R. A. (2017). Functional Thinking for Managing Challenging Behavior. Intervention in School and Clinic. 1-7. https://doi.org/10.1177/1053451217712972

Blanton, M., Brizuela, B. M., Gardiner, A. M., Sawrey, K., Newman-owens, A., Blanton, M., Gardiner, A. M., \& Newman-owens, A. (2016). A Learning Trajectory in 6-Year-Olds' Thinking About Generalizing Functional Relationships. Journal for Research in Mathematics Education. 46(5), 511-558. https://doi.org/10.5951/jresematheduc.46.5.0511

Blanton, M. L., \& Kaput, J. J. (2004). Elementary Grades Students' Capacity For Functional Thinking. Proceedings of the 28th Conference of the International Group for the Psychology of Mathematics Education. 2. 135-142. https://www.emis.de/proceedings/PME28/RR/RR033_Blanton.pdf

Blanton, M. L., \& Kaput, J. J. (2005). Helping Elementary Teachers Build Mathematical Generality into Curriculum and Instruction. ZDM. 37(1). https://doi.org/10.1007/BF02655895

Blanton, M. L. and James J. K. (2011) . Functional Thinking as a Route Into Algebra in the Elementary Grades. https://page-one.springer.com/pdf/preview/10.1007/978-3-642-17735-4_2

Blanton, M., Stephens, A., Knuth, E., Gardiner, A. M., Isler, I., Kim, J., Blanton, M., Knuth, E., Gardiner, A. M., \& Kim, J. (2015). The Development of Children's Algebraic Thinking: The Impact of a Comprehensive Early Algebra Intervention in Third Grade. Journal for Research in Mathematics Education. 46(1), 39-87. https://doi.org/10.5951/jresematheduc.46.1.0039

Brizuela, B. M. (2015). Children's Use of Variables and Variables Notation to Represent Their Algebraic Ideas. Mathematical Thinking and Learning, 1-30. https://doi.org/10.1080/10986065.2015.981939

Carlson, M., Sally J., Edward C., Sean L., and Eric H. (2002). Applying Covariational Reasoning While Modeling Dynamic Events: A Framework and a Study. Journal for Research in Mathematics Education 33(5):352-78. https://www.jstor.org/stable/4149958

Carpenter, T. P., \& Levi, L. (2000). Developing conceptions of algebraic reasoning in the primary grades. Wisconsin Center for Educational Research. 21. https://files.eric.ed.gov/fulltext/ED470471.pdf

Cooper, T. O. M. (2006). Using Repeating Patterns to Explore Functional Thinking. 11(1):9-14. https://files.eric.ed.gov/fulltext/EJ793907.pdf

Creswell. (2012). Educational Research Fourth Edition. Pustaka Pelajar. ISBN 978-602-229-474-0 
Doorman, M., Drijvers, P., Gravemeijer, K., Boon, P., \& Reed, H. (2012). Tool use and Development of the Function Concept: from Repeated Calculations to Functional Thinking. International Journal of Science and Mathematics Education. 1243-1267. https://doi.org/10.1007/s10763012-9329-0

Driscoll. M. (2003). Fostering algebraic thinking. A guide for teachers grades 6-10. Portsmouth, NH: Heinemann. https://files.eric.ed.gov/fulltext/ED476802.pdf

Kaput, J. (2000). Teaching and learning a new algebra. In E. Fennema, \& T. Romberg (Eds.), Mathematics classrooms that promote understanding (pp. 133-155). Mahwah, NJ: Lawrence Erlbaum Associates.

http://www.educ.fc.ul.pt/docentes/jponte/DA/DA-TEXTOS/Kaput_99AlgUnd.pdf

Koedinger, K. R. and Nathan, M. J. (2004). The Real Story Behind Story Problems: Effects of Representations on Quantitative Reasoning. The Journal of the Learning Sciences. 13(2):12964.

https://www.researchgate.net/profile/Kenneth_Koedinger2/publication/280786796_The_Real_St ory_behind_Story_Problems_Effects_of_Representations_on_Quantitative_Reasoning/inline/js Viewer/568bdda308ae8445f58dbd11?inViewer=1\&pdfJsDownload=1\&origin=publication_deta il\&previewAsPdf=false

Machmurotun, S. (2014). The Thinking Ability of Students in Solving Mathematics. Journal Pendidikan Matematika. 2(2): 237-48.

http://seminar.uny.ac.id/icriems/sites/seminar.uny.ac.id.icriems/files/proceeding2018/ME86_Eva $\% 20 \mathrm{Dwi} \% 20$ Minarti.pdf

Markworth, K. A. (2010). Growing and Growing: Promoting Functional Thinking With Geometric Growing Patterns. A Dissertation Submitted to the Faculty of the University of North Carolina at Chapel Hill in Partial Fulfillment of the Requirements for the Degree of Doctor of Philosophy in the School of Education. Chapel Hill

Mceldoon, K. L., and Rittle-Johnson. (2010). Assessing Elementary Students Functional Thinking Skills. The Case of Function Tables

https://peabody.vanderbilt.edu/docs/pdf/PRO/ATME_McEldoonandRittle-JohnsonPMENApaper_2010.pdf

Muir, T. \& Livy, S. (2015). Two of Everything Developing Functional Thinking in Primary Grades Through Children's Literature. In APMC. Vol. 20 (1). https://files.eric.ed.gov/fulltext/EJ1093237.pdf

Stephens, A., Blanton, M., Strachota, S., Knuth, E., \& Gardiner, A. (2017). The Interplay between Students' Understandings of Proportional and Functional Relationships. Proceedings of the 39th Annual Meeting of the North American Chapter of the International Group for the Psychology of Mathematics Education. Indianapolis, IN Hoosier Association of Mathematics Teacher Educators. 251-258. https://files.eric.ed.gov/fulltext/ED581309.pdf

Stephens, A. C., Blanton, M. L., Knuth, E. J., Marum, T., \& Gardiner, A. M. (2011). From Recursive Pattern To Correspondence Rule: Developing Students' Abilities To Engage in Functional Thinking. Proceedings of the 34th Annual Meeting of the North American Chapter of the International Group for the Psychology of Mathematics Education. Kalamazoo, MI: Western Michigan University.

https://www.researchgate.net/profile/Isil_Isler-

Baykal/publication/304526974_From_recursive_pattern_to_correspondence_rule_Developing_s tudents\%27_abilities_to_engage_in_functional_thinking/inline/js Viewer/5772691508aeef01a0b 62a99?inViewer=1\&pdfJsDownload=1\&origin=publication_detail\&previewAsPdf=false 
Stephens, A. C., Fonger, N., Strachota, S., Isler, I., Blanton, M., Knuth, E., \& Murphy Gardiner, A. (2017). A Learning Progression for Elementary Students 'Functional Thinking A Learning Progression for Elementary Students' Functional. Mathematical Thinking and Learning, 19(3), 143-166. https://doi.org/10.1080/10986065.2017.1328636

Subanji. (2011). Teori Berpikir Pseudo Penalaran Kovariasional. Universitas Negeri Malang. ISBN: 979.495.963.4

Tanişli, D. 2011. "Functional Thinking Ways in Relation to Linear Function Tables of Elementary School Students." Journal of Mathematical Behavior 30(3):206-23

Tanis, D. (2011). Functional Thinking Ways in Relation to Linear Function Tables of Elementary School Students. Journal of Mathematical Behavior, 30(3), 206-223. https://doi.org/10.1016/j.jmathb.2011.08.001

Warren, E. A., \& Cooper. (2012). Exploring Young Students Functional Thinking. Proceeding of the 35th Conference of the International Group for the Psychology of Mathematics Education. 4. 75-84. https://dialnet.unirioja.es/descarga/articulo/4268866.pdf

Warren, E. A., Cooper, T. J., \& Lamb, J. T. (2006). Investigating Functional Thinking in the Elementary Classroom : Foundations of Early Algebraic Reasoning. Mathematical Behavior. 25, 208-223. https://doi.org/10.1016/j.jmathb.2006.09.006

Warren, E., \& Cooper, T. O. M. (2005). Introducing Functional Thinking in Year 2: a Case Study of Early Algebra Teaching. In Contemporary Issues in Early Childhood. 6(2), 150-162. https://doi.org/10.2304/ciec.2005.6.2.5

Wilkie, K. J. (2004). Learning to like Algebra through Looking. APMC. 19(4). https://files.eric.ed.gov/fulltext/EJ1093277.pdf

Wilkie, K. J. (2014). Upper Primary School Teachers' Mathematical Knowledge for Teaching Functional Thinking in Algebra. Journal of Mathematics Teacher Education. 17(5). https://doi.org/10.1007/s10857-013-9251-6

Wilkie, K. J. (2015). Learning to Teach Upper Primary School Algebra : Changes to Teachers' Mathematical Knowledge for Teaching Functional Thinking. Mathematics Education Research Journal. 28 (2). 245-275. https://doi.org/10.1007/s13394-015-0151-1

Wilkie, K. J., \& Clarke, D. M. (2015). Developing Students' Functional Thinking in Algebra Through Different Visualisations of a Growing Pattern's Structure. Mathematics Education Research Journal, 223-243. https://doi.org/10.1007/s13394-015-0146-y

Yuniati, S., Nusantara, T., Subanji, \& Made S., I. (2019). The use of Multiple Representation in Functional Thinking. International Journal of Recent Technology and Engineering, 8(1C2), 672-678. https://www.ijrte.org/wp-content/uploads/papers/v8i1C2/A11120581C219.pdf

Yuniati, S., \& Suparjono. (2019). Model Representasi Matematis Siswa Kelas IV dalam Menyelesaikan Soal Cerita. MaPan 7(2):249-60. https://www.researchgate.net/publication/338508181_MODEL_REPRESENTASI_MATEMAT IS_SISWA_KELAS_IV_DALAM_MENYELESAIKAN_SOAL_CERITA/inline/jsViewer/5e1 876ba299bf10bc3a109bb?inViewer=1\&pdfJsDownload=1\&origin=publication_detail\&preview AsPdf $=$ false 